\title{
Light and electron microscopic studies on turbot Psetta maxima infected with Enteromyxum scophthalmi: histopathology of turbot enteromyxosis
}

\author{
R. Bermúdez ${ }^{1, *}$, A. P. Losada ${ }^{2}$, S. Vázquez ${ }^{2}$, M. J. Redondo ${ }^{3}$, P. Álvarez-Pellitero ${ }^{3}$, \\ M. I. Quiroga ${ }^{2}$ \\ ${ }^{1}$ Departamento de Anatomía y Producción Animal and ${ }^{2}$ Departamento de Ciencias Clínicas Veterinarias, \\ Facultad de Veterinaria, Universidad de Santiago de Compostela, 27002 Lugo, Spain \\ ${ }^{3}$ Instituto de Acuicultura de Torre la Sal, Consejo Superior de Investigaciones Científicas, 12595 Ribera de Cabanes, \\ Castellón, Spain
}

\begin{abstract}
In the last decade, a new parasite that causes severe losses has been detected in farmed turbot Psetta maxima (L.), in north-western Spain. The parasite was classified as a myxosporean and named Enteromyxum scophthalmi. The aim of this study was to characterize the main histological changes that occur in E. scophthalmi-infected turbot. The parasite provoked catarrhal enteritis, and the intensity of the lesions was correlated with the progression of the infection and with the development of the parasite. Infected fish were classified into 3 groups, according to the lesional degree they showed (slight, moderate and severe infections). In fish with slight infections, early parasitic stages were observed populating the epithelial lining of the digestive tract, without eliciting an evident host response. As the disease progressed, catarrhal enteritis was observed, the digestive epithelium showed a typical scalloped shape and the number of both goblet and rodlet cells was increased. Fish with severe infections suffered desquamation of the epithelium, with the subsequent release of parasitic forms to the lumen. The dislodged enterocytes underwent anoikis, a mode of apoptosis triggered by the loss of anchorage, which might facilitate spreading of the parasite. Lymphohaematopoietic depletion was also observed, mainly in head kidney and spleen, which could contribute to the high virulence of this parasite.
\end{abstract}

KEY WORDS: Turbot · Psetta maxima · Apoptosis · Anoikis · Myxosporea · Enteromyxum scophthalmi $\cdot$ Morphopathology $\cdot$ Parasite

Resale or republication not permitted without written consent of the publishe

\section{INTRODUCTION}

Members of the phylum Myxozoa are common parasites of fish and some invertebrates and are also the causative agents of several economically important diseases in wild and farmed fish stocks (Feist 2008). In the last few years, due to the phenomenal increase in fish aquaculture, concerns regarding myxosporean infections have increased significantly (Diamant et al. 1994, Kent et al. 2001, Lom \& Dyková 2006, Palenzuela 2006, Feist 2008). Although enormous advances have been made in the last few decades in aspects of myxozoan phylogeny and taxonomy (Fiala 2006, Bartosová et al. 2009), the whole life cycle of many species remains unknown. Due to this fact and to the lack of effective treatments (Yokoyama et al. 1990, Athanassopoulou et al. 2004, Bermúdez et al. 2006a), prevention and control of myxosporean infections is particularly difficult.

Although the vast majority of Myxosporea develops in any part of the fish body (Lom \& Dyková 1995, 2006, Molnár 2007), few of them are described from enteric locations (Lom \& Dyková 1995, 2006, Padrós et al. 2001, Álvarez-Pellitero et al. 2008). Ceratomyxa shasta, causing an important disease in salmonids, invades the intestinal epithelium, though the infection may become 
disseminated to several organs (Bartholomew et al. 1989). Among myxosporeans with only enteric infection, species of the genus Enteromyxum deserve special mention. E. leei causes high mortalities in the sea bream Sparus aurata L. and other sparids in Mediterranean areas (Padrós et al. 2001, Álvarez-Pellitero et al. 2008, Fleurance et al. 2008).

Another species was initially described in farmed turbot, Psetta maxima (L.), in north-western Spain, causing rates of morbidity and mortality of $100 \%$ in all fish infected during the epizootic outbreaks (Branson et al. 1999). Infected fish suffer a progressive destruction of the gut due to severe catarrhal enteritis that leads to a cachectic syndrome and death. By means of morphological and ribosomal RNA studies, this parasite was classified as a myxozoan and named Enteromyxum scophthalmi (Palenzuela et al. 2002).

Studies concerning Enteromyxum scophthalmi infections in turbot have been focused on the epidemiology and immunopathology of the disease (Palenzuela et al. 2002, Redondo et al. 2004, Bermúdez et al. 2006b, Quiroga et al. 2006, Sitjà-Bobadilla et al. 2006, 2008) rather than on the lesions that it induces in host tissues. Therefore, scarce data exist on the histological changes that enteromyxosis causes in turbot.

The aim of the present study was to characterize the histological changes that occur in Enteromyxum scophthalmi-infected turbots by using light and electron microscopy studies, in order to obtain a complete profile of the disease from a morphopathological point of view.

\section{MATERIALS AND METHODS}

Animals. Infected juvenile turbots Psetta maxima (weight: 50 to $300 \mathrm{~g}$ ) were obtained in north-western Spain from several Enteromyxum scophthalmi-affected farms suffering serious mortality records due to the parasite (Redondo et al. 2004, Redondo 2005, Quiroga et al. 2006), as well as from experimental infections performed orally or by cohabitation (mean weight: $161 \mathrm{~g}$ ) (Redondo et al. 2002, 2004, Bermúdez et al. 2006a,b, Sitjà-Bobadilla et al. 2006). Uninfected control fish were hatched and reared in a flow-through supply of cartridge-filtered (1 $\mu \mathrm{m}$ mesh) and UV-irradiated seawater, ensuring a microbe-free water supply.

Three groups of infected fish were established according to the lesional degree: (1) slight, (2) moderate and (3) severe infections. The criteria employed to classify these individuals are summarized in Table 1.
Sampling procedure. Fish were sacrificed by chilling on ice and spinal cord severance or by overexposure to the anaesthetic MS-222 (Sigma). Tissue samples were collected from the gastrointestinal tract (oesophagus, stomach, pyloric caeca and anterior, medium and posterior gut), kidney, spleen, liver, pancreas, heart, muscle, skin and gills.

Light microscopy (LM). The aforementioned fish tissues were routinely fixed in $10 \%$ neutral buffered formalin and embedded in paraffin. Thin sections (1 to $3 \mu \mathrm{m}$ ) were stained with haematoxylin and eosin (HE), Giemsa, toluidine blue and periodic acid-Schiff (PAS) methods.

Transmission electron microscopy (TEM). Small pieces of gut, spleen, kidney and detached intestinal mucosa were fixed in $2.5 \%$ glutaraldehyde in $0.1 \mathrm{M}$ cacodylate buffer $(\mathrm{pH} 7.3)$, for $1 \mathrm{~h}$ at $4^{\circ} \mathrm{C}$. The liquid present in the digestive tract of some infected fish was collected with a syringe. After confirming the presence of parasitic stages by LM, this liquid was centrifuged at $365 \times g$ and the pellet fixed as above. Samples were post-fixed in $1 \%$ (w/v) cacodylic $\mathrm{OsO}_{4}$, dehydrated through a graded ethanol series, and embedded in Spurr's or epoxy resin. Semi-thin sections $(500 \mathrm{~nm})$ were stained with toluidine blue, while ultrathin sections $(80 \mathrm{~nm})$ were double stained with uranyl acetate and lead citrate.

\section{RESULTS}

\section{Clinical signs and macroscopic lesions}

Initial signs of infection included lethargy and anorexia. As the disease progressed to severe, affected turbot Psetta maxima showed external signs consisting of emaciation, endophthalmia and a typical prominent bony ridge on the skull (Fig. 1). The main macroscopic lesions consisted of the presence of serosanguineous effusion in the coelomic cavity and hyperemic areas

Table 1. Psetta maxima and Enteromyxum scophthalmi. Classification of infected turbot into 3 groups, according to their lesional degree: absent $(-)$, light $(+)$, moderate $(++)$ and severe $(+++)$. Infection intensity in each intestinal fold was evaluated in the histological sections on a scale of $1+$ to $3+$, according to the number of parasite stages present in microscope fields at $300 \times$ magnification (Quiroga et al. 2006). E. scophthalmi developmental stages are given according to Redondo et al. (2004). Desquam.: desquamation; Inflamm. cells: presence of inflammatory cells in lamina propria-submucosa

\begin{tabular}{|c|c|c|c|c|c|c|}
\hline \multirow{2}{*}{$\begin{array}{l}\text { Lesional } \\
\text { degree }\end{array}$} & \multicolumn{3}{|c|}{ Infected digestive folds } & \multirow{2}{*}{$\begin{array}{c}\text { E. scoph. } \\
\text { stages }\end{array}$} & \multirow{2}{*}{ Desquam. } & \multirow{2}{*}{$\begin{array}{l}\text { Inflamm } \\
\text { cells }\end{array}$} \\
\hline & Ext. signs & $\%$ & Intensity & & & \\
\hline Slight & $-/+$ & $<30$ & + & $1-2$ & - & $-/+$ \\
\hline Moderate & ++ & $30-80$ & ++ & $2-3$ & $+/++$ & +/++ \\
\hline Severe & +++ & $>80$ & +++ & $2-5$ & +++ & $+/+++$ \\
\hline
\end{tabular}


affecting intestinal serosal surfaces, as well as of accumulation of liquid within the digestive tract. Mild splenomegaly was occasionally seen (Fig. 1).

\section{Histopathological changes in the course of infection}

Both the morphopathological changes and the intensity of the lesions varied in the infected fish as the disease progressed. All developmental myxosporidian stages described here occurred in an intercellular position. Turbot belonging to the control group did not show any histological changes and no myxozoan stages occurred in these fish.

\section{Slight infections}

LM observations. The most evident alteration was the occurrence of early developmental stages of Enteromyxum scophthalmi within the basal part of the epithelium of the digestive tract, without eliciting noticeable histological changes (Fig. 2). In general, the infection was first detected in the pyloric caeca or the anterior intestine, and, from there, the parasite proliferated and extended both upwards and downwards through the digestive tract. Few parasites infiltrated the lining epithelium, and only some intestinal folds were affected. Some rounded, basophilic structures deserve special attention, since they resembled either early stages of the myxozoan (trophozoites) or apoptotic figures, hindering the histological diagnosis of the disease (Fig. 3). An additional finding in fish with scarce infection was the increase in the relative number of goblet and rodlet cells in the intestinal mucosa, in some cases proximal to the parasite (Figs. 4 to 6). In contrast, inflammatory infiltrates, when present, were slight and mainly consisted of mononuclear cells located within the lamina propria-submucosa and/or the basal part of the digestive epithelium. No evident changes in the other studied organs of fish with slight infection were noticed.

TEM observations. The epithelial architecture of infected turbot did not substantially differ from the normal simple columnar epithelium. Cells were cylindrical and polarized, with an apical side possessing microvilli forming the brush border, a basolateral side adhering to the basement membrane and adhering laterally to each neighbouring cell through diverse specialized intercellular junctions. Most enterocytes showed the normal structure with a basally located nucleus, numerous mitochondria, rough endoplasmic reticulum (RER) and some lysosomes. Rodlet and goblet cells were easily observed within a single TEM field due to their increased number, and in some cases they appeared releasing their content (Fig. 7). In only a few cases, epithelial lining cells showed changes in their arrangement and structure. These cells were generally in close contact with parasitic forms and showed a more electron-lucid cytoplasm accompanied with loss of cytoplasmic organelles and changes in the organization of the chromatin pattern (Fig. 7). Some parasite plasmodia were seen closely attached to 2 or more adjacent epithelial cells by means of prominent and numerous interdigitated cytoplasmic projections, forming specialized junctions with the membrane of the host cell (Fig. 8).

\section{Moderate infections}

LM observations. As the infection progressed, both the number of Enteromyxum scophthalmi stages within the epithelium and the amount of infected gastrointestinal areas increased (Fig. 9). Furthermore, different developmental stages of the parasite could be observed since they matured synchronically. The parasites appeared in the mucosa of all portions of the digestive tract, but the highest parasitic burden was present in the pyloric caeca and anterior gut. A few parasitic forms were also detected in the lining epithelium of the stomach and in the gastric glands, but only scant mucosal damage was observed at this level.

Fish with moderate infections showed mild to moderate catarrhal enteritis, with the epithelial lining of some gastric areas and intestinal folds displaying a typical scalloped apical margin and vacuolation at the base of the epithelium (Figs. $9 \& 10$ ). A few enterocytes, mostly those located close to the parasites, displayed hypertrophied nuclei with central migration of chromatin and peripheral clearing of the nucleus (Fig. 10). Though, digestive areas displaying a lesser parasitic load even exhibited an almost normal architecture. The number of rodlet and goblet cells remained unchanged or even suffered a slight reduction, sometimes accompanied by loss of their content, when compared to turbot with slight infections.

The inflammatory reaction present in the lamina propria-submucosa was scarce or moderate, but it usually occurred in those folds where the number of parasites was high. In these cases, mild dilation of submucosal sanguineous capillaries and lymphangiectasia could be seen (Fig. 11). In addition, some small, rounded immune cells identified as lymphocytes were observed infiltrating the basal part of the epithelium (Fig. 12). However, a direct relationship between the number of parasitic forms populating the epithelium and the magnitude of the inflammatory response was not always evident, that is, turbot with a moderate 

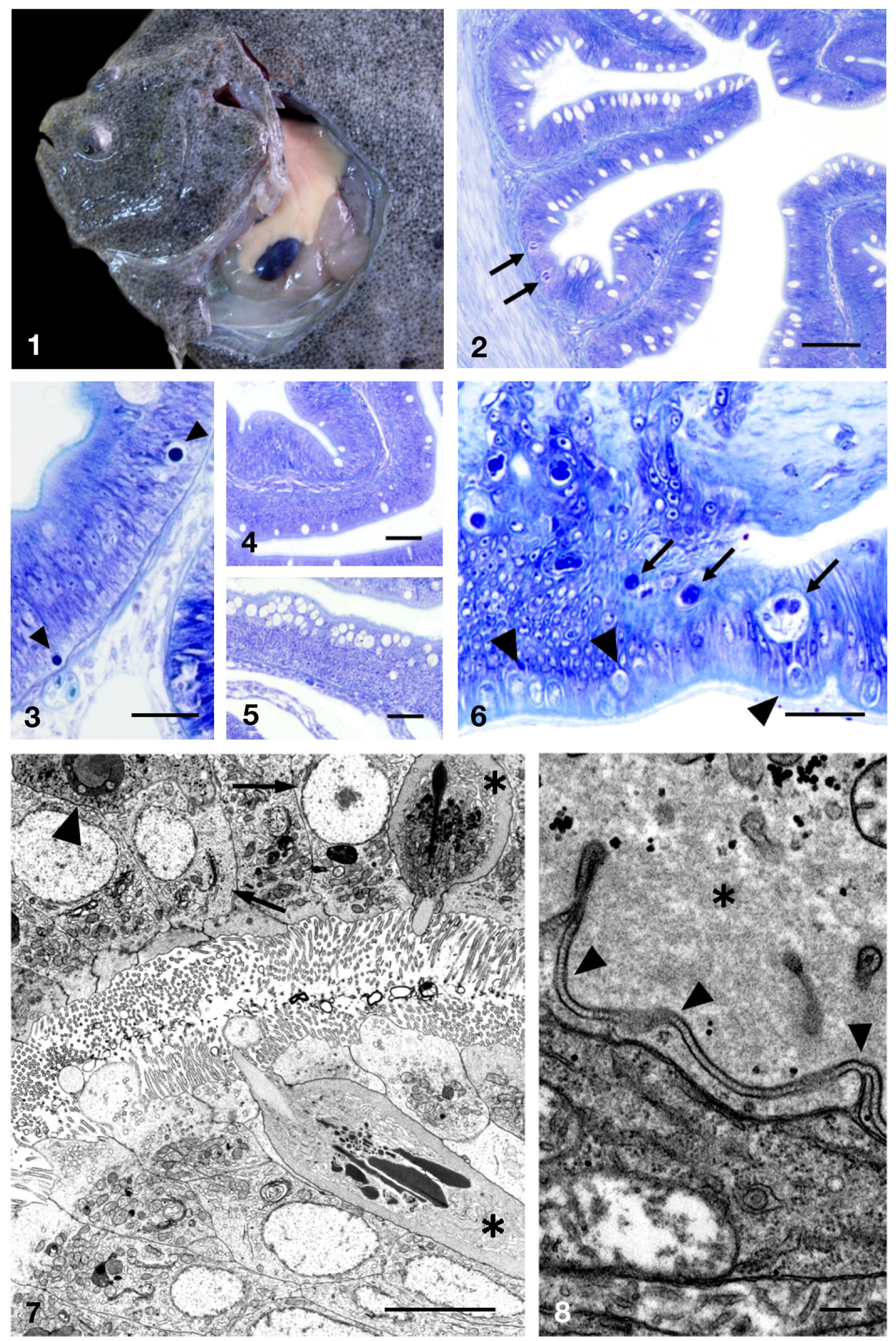
number of parasite forms could exhibit either evident or mild inflammatory infiltrates. Occasionally, small melanomacrophage centres (MMCs) were detected within the lamina propria-submucosa, generally close to submucosal vessels (Fig.13).

Within the lymphohaematopoietic organs (thymus, spleen and anterior kidney), an increase in the number of cells with either necrotic or apoptotic shape occurred, and a scarce number of parasitic forms, mostly in apoptosis and sometimes engulfed by macrophages, were observed at this level. The MMCs present in spleen and anterior kidney were generally bigger and more abundant than those that occurred in fish with slight infections.

The rest of the studied organs showed a normal structure although Enteromyxum scophthalmi stages were identified in the gill filaments, adhering to the fish tegument and also in the bile ducts. No evident host response was observed at these locations.

TEM observations. The alteration of enterocytes, mainly those in close contact with the parasite, was notable, showing swollen mitochondria with effacement of cristae (Fig. 14), loss of microvilli, chromatin condensation and decrease in cytosol electrondensity (Fig. 15). Pathological changes in the intestinal folds also included edema and mild vacuolation at the level of basal lamina. As the disease progressed, parasitic stages further increased in number and size, and both proliferative and less abundant sporogonic stages were observed. Some inflammatory cells were detected at the basal level of the epithelium (mainly lymphocytes) and in the lamina propria-submucosa (lymphocytes, granulocytes and macrophages).

\section{Severe infections}

LM observations. In more advanced infections, parasitic stages were seen in all the studied portions of the digestive tract, from the stomach to the rectum. The epithelium, showing the typical scallop shape, suffered critical damage, with the enterocytes displaying a foamy appearance and either necrotic or apoptotic morphologies (Fig. 16). The rodlet and goblet cells underwent a dramatic decrease in their number at this phase of infection, being almost absent in some intestinal folds. Finally, the epithelial lining detached from the subepithelial tissue and indicators of apoptosis, namely, cell rounding and shrinkage, chromatin condensation and nuclear fragmentation, were present in the isolated dislodged enterocytes (Fig. 17). Parasitic stages accompanied desquamated epithelial cells which formed clusters of debris that were released to the lumen (Fig. 17). Sometimes, such dislodged cells showed large rounded empty spaces (Fig. 18).

As a consequence of epithelial detachment, completely denuded folds could be seen during this phase of infection (Fig. 19). In a few turbot some regeneration of the epithelial lining was observed after detachment and, in these cases, intestinal folds appeared covered with squamous or low cubic cells (Fig. 20). The number of Enteromyxum scophthalmi sporogonic stages increased in this phase, though few mature spores, showing metachromasia of their polar capsule with toluidine blue technique, were detected in few fish.

Secondary bacterial infections were occasionally found in association with the presence of Enteromyxum scophthalmi. In these cases, bacteria appeared in the lumen and/or attached to the apical surface of enterocytes. The inflammatory infiltrates observed in the lamina propria-submucosa did not substantially differ from those observed in fish with moderate infections. In some fish the inflammatory reaction was extremely widespread, but in others, which showed evident epithelial damage and huge parasitic load, the recruitment of inflammatory cells was limited. Several cells in the lamina propria-submucosa displayed early signs of necrosis characterized by cytoplasmic eosinophilia and nuclear pyknosis. The MMCs at this level, when present, were not as evident as in fish with moderate infections. The

Figs. 1 to 8. Psetta maxima and Enteromyxum scophthalmi. Fig. 1. Macroscopic photography of an E. scophthalmi-infected turbot $P$. maxima with prominent bony ridges and exophthalmia due to cachexy. Note also the generalized hyperaemia in the organs within the celomic cavity, splenomegaly and dilated gut. Turbot intestines from control (Fig. 4) and infected (Figs. 2 \& 3, 5 \& 6) fish corresponding to slight infection. Light microscopy micrographs were stained with toluidine blue. Fig. 2. Parasitized pyloric caeca without evident histological changes. Early parasitic forms appear at the base of the epithelium (arrows). Scale bar $=60 \mu \mathrm{m}$. Fig. 3. Basophilic, rounded forms (arrowheads), mainly located at the base of the digestive epithelium, that may resemble either myxosporean trophozoites or apoptotic patterns. Scale bar $=20 \mu \mathrm{m}$. Fig. 4. Histological section of the medium intestine of a control turbot, displaying typical enteric morphology with a moderate number of mucous cells. Scale bar $=30 \mu \mathrm{m}$. Fig. 5 . Histological section of the medium intestine of an E. scophthalmi-infected turbot, showing a distinct increase in the number of goblet cells when compared with Fig. 4. Scale bar $=30 \mu \mathrm{m}$. Fig. 6. Different developmental stages of E. scophthalmi (arrows) within the epithelial lining of the stomach accompanied by numerous rodlet cells (arrowheads). Scale bar $=20 \mu \mathrm{m}$. Fig. 7. TEM micrograph of the pyloric caeca of an infected turbot. Some enterocytes display a more electron-lucid cytoplasm and changes in the arrangement of chromatin pattern (arrows). Two secreting rodlet cells (asterisks), as well as a parasitic stage (arrowhead) are shown. Scale bar $=5 \mu \mathrm{m}$. Fig. 8. Myxosporean plasmodium (asterisk) attached to the adjacent epithelial cells by means of numerous cytoplasmic projections (arrowheads). Scale bar $=0.2 \mu \mathrm{m}$ 

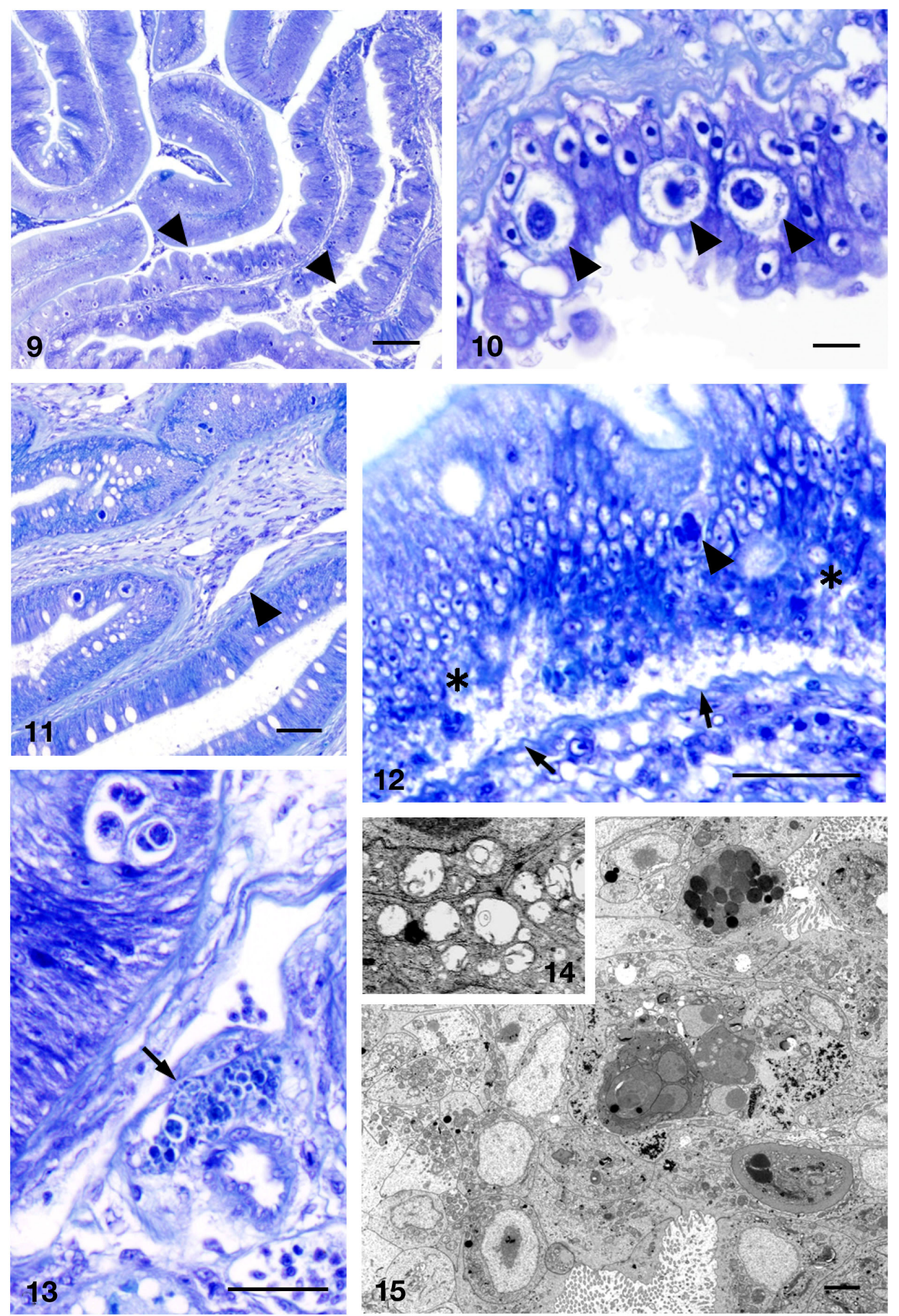
dilatation of blood and lymphatic vessels of the lamina propria-submucosa was extremely apparent (Fig. 21).

In fish with severe digestive lesions, cellular depletion became evident in lymphohaematopoietic regions of spleen and kidney, but this feature was not always accompanied by a high number of necrotic and apoptotic cells.

TEM observations. The enterocytes showed evident pathological changes, including loss of adhesion to the basement lamina (with edematous spaces clearly demarcated by deposition of amorphous, electronlucent material), and disruption of lateral cell-cell connections. Thus, enterocytes became isolated and changed to a spherical shape, with loss of polarization and disorganization or loss of the apical brush border (Fig. 22). Clusters of rounded, degenerated and detached epithelial cells, some of which contained parasitic forms, were observed. Some of them showed empty spaces of different sizes corresponding to those observed in LM (Fig. 23). Cells from the clusters with empty spaces displayed peripheral migration of the nucleus. Some isolated epithelial cells showed evident apoptotic alterations, including cell rounding and fragmentation and/or nuclear condensation (Figs. 24 \& 25).

Significant ultrastructural changes were present at the level of the connective tissue underlying the mucosal epithelium, appearing thin and grossly disorganized (Figs. 26 \& 27). In some cases, many cells of the lamina propria, as well as cells from haematopoietic areas of the spleen and kidney, showed advanced signs of necrosis, such as cytoplasmic vacuolation and karyorrhexis.

\section{DISCUSSION}

Turbot Psetta maxima infected with Enteromyxum scophthalmi became emaciated and finally died with a cachectic syndrome. The external appearance of these fish and the joint hyperaemic appearance of the gut were considered by Branson et al. (1999) to be pathog- nomonic signs of the disease, although these lesions might also be seen in fish suffering from other chronic diseases. Of the histological techniques used, PAS, Giemsa and toluidine blue proved to be the most useful stains to identify the parasite in tissues. Parasitic stages occurred almost exclusively within the epithelium throughout the digestive tract. However, some developmental forms were occasionally detected and confirmed by in situ hybridization (results not shown) in the enteric submucosa and in other locations, such as the gill filaments, skin, bile ducts and lymphohaematopoietic organs (spleen and kidney), as previously described by Redondo et al. (2002, 2004). The few parasites found in these organs did not produce lesions, which suggests that such organs might be involved in the invasion or dispersion of the parasite, but they are not target organs. Redondo et al. (2004) also found parasite stages in blood smears, which indicate the role of the vascular system in the parasite's spreading within the fish. These early stages in the digestive submucosa and lymphohaematopoietic organs may have undergone erratic migration, as they occasionally appeared to be engulfed in macrophages, as previously reported (Redondo et al. 2004).

The histopathological study demonstrated the harmful effect of the parasite chiefly on the digestive epithelium. In addition, a variable number of inflammatory cells occurred in the lamina propria-submucosa, as well as in the basal part of the lining epithelium. In several other myxosporean infections no inflammatory response was associated with the presence of the parasite (Moran et al. 1999, Ali et al. 2003, Barassa et al. 2003, Adriano et al. 2005). However, Enteromyxum scophthalmi can elicit a strong inflammatory host response in addition to the direct deleterious effects on the gastrointestinal mucosa. Other enteric myxozoans, such as Ceratomyxa shasta (Bartholomew et al. 1989) and Enteromyxum leei (Álvarez-Pellitero et al. 2008, Fleurance et al. 2008) also induce an important inflammatory reaction. In the case of $E$. leei, both the severity of the histological lesions and the elicited immune re-

Figs. 9 to 15. Psetta maxima and Enteromyxum scophthalmi. Photographs of turbot tissues infected with E. scophthalmi corresponding to moderate infection. Light microscopy micrographs were stained with toluidine blue. Fig. 9. Different developmental stages of E. scophthalmi in the pyloric caeca. The affected intestinal folds acquire a typical scalloped apical margin (arrowheads), while uninfected folds show physiological morphology. Scale bar $=60 \mu \mathrm{m}$. Fig. 10. Enterocytes proximal to parasites (arrowheads), showing structural changes that mainly consisted of hypertrophy of the nuclei with central migration of chromatin and peripheral clearing of the nucleus. Scale bar $=6 \mu \mathrm{m}$. Fig. 11. Slight inflammatory reaction in the lamina propria-submucosa of anterior intestine, mainly compounded by mononuclear cells. Note the dilation of sanguineous capillaries in the submucosa (arrowhead). Scale bar $=30 \mu \mathrm{m}$. Fig. 12. Inflammatory infiltrates, mainly compounded by mononuclear cells, located at the basal part of the epithelium of the anterior intestine. Note also the vacuolization (asterisks), the incipient dislodging at the basis of the epithelial lining (arrows) and the parasitic form (arrowhead). Scale bar $=20 \mu \mathrm{m}$. Fig. 13. Melanomacrophage centre (arrow) located close to a vessel within the lamina propria-submucosa of the anterior intestine. Scale bar $=20 \mu \mathrm{m}$. Fig. 14 . Detail of the enterocyte mitochondrial damage, with effacement of the cristae. Fig. 15. TEM micrograph of pyloric caeca. E. Scophthalmi stage can be observed attached to the epithelial cells. Note the alteration of the enterocytes, which display chromatin condensation and decrease in the cytosol density. Scale bar $=2 \mu \mathrm{m}$ 

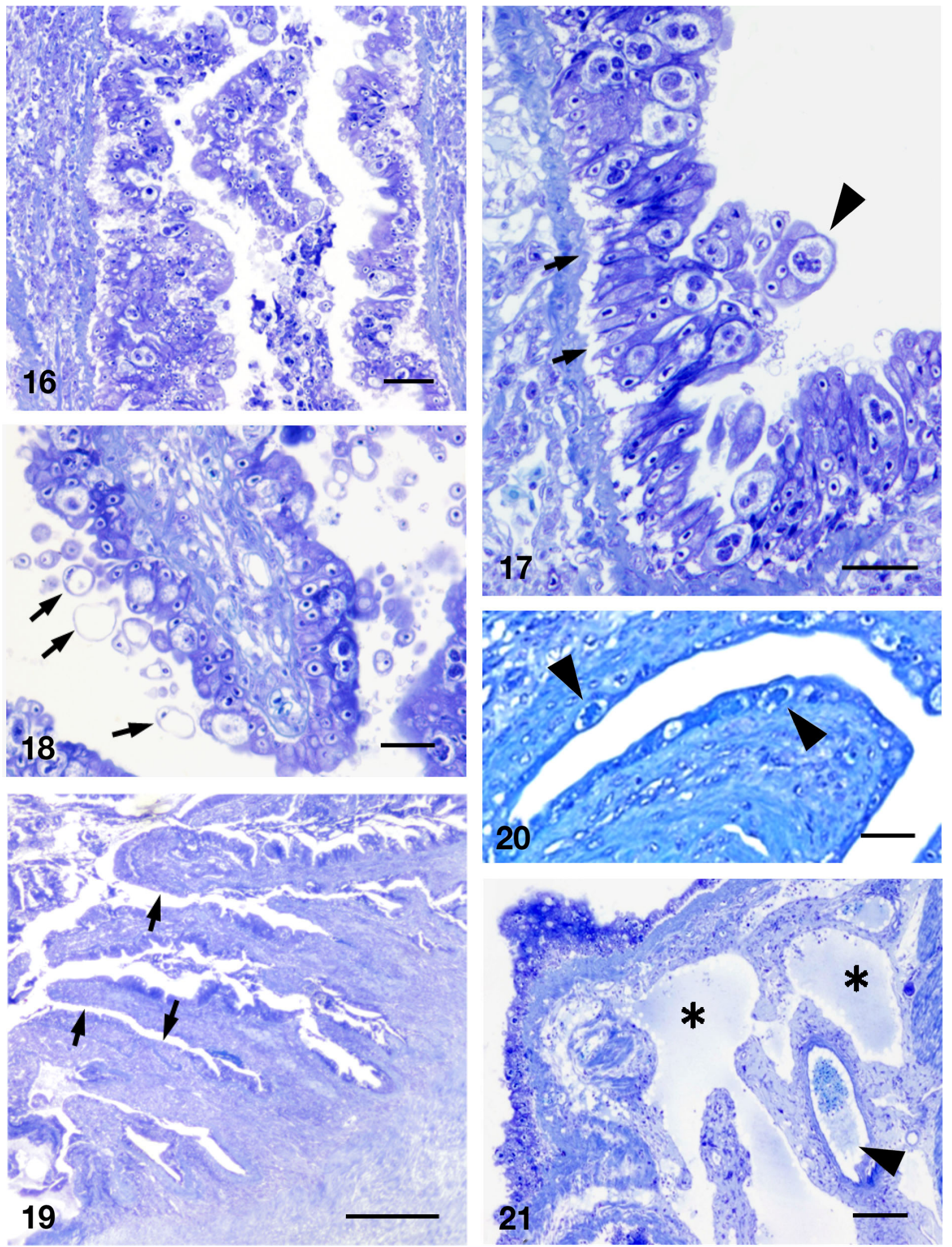
sponse vary greatly depending on the host species (Padrós et al. 2001, Álvarez-Pellitero et al. 2008, Fleurance et al. 2008). Similarly, the current results on turbot enteromyxosis demonstrated that the inflammatory response in the digestive tract was not always correlated with the number of parasites populating the epithelium, as has been previously reported (Bermúdez et al. 2006b, Sitjà-Bobadilla et al. 2006, 2007).

An interesting finding was the initial increase in the amount of both rodlet and goblet cells, followed by a decrease in their number in fish suffering severe infections (Vigliano et al. 2004). Such cell types are accepted to be involved in fish response to different pathogens, and the modification in their relative number has been described for several fish species suffering diverse infections or parasitic diseases (Dezfuli et al. 2008, Reite 2005, Mazon et al. 2007, Fleurance et al. 2008). The low number of mucous and rodlet cells found in fish with severe infections may simply be attributed to the serious damage of the epithelium, which becomes unable to support these cells.

In the present study, developmental (proliferative and sporogonic) stages of Enteromyxum scophthalmi were found in the digestive epithelium, and the increasing severity of damage correlated with the proliferation and maturation of the parasite and subsequent progression of the infection. A similar situation was described by Redondo et al. $(2002,2004)$ for turbot enteromyxosis and by Álvarez-Pellitero et al. (2008) for E. leei infecting Diplodus puntazzo. In incipient phases of turbot enteromyxosis, the similarity between the early developmental stages of E. scophthalmi and cells undergoing apoptosis was noteworthy, especially when both of them were located at the basal level of the epithelium (Redondo et al. 2004). This fact hinders the histological diagnosis of the disease at the beginning of the infection, but the employment of specific histological techniques (TUNEL, anti-caspase-3 and anti-E. scophthalmi antibodies and in situ hybridization) may be used to distinguish between parasitic forms and apoptotic cells (Redondo 2005, authors' unpubl. obs.).

Enteromyxum scophthalmi plasmodia occupied an intercellular position attached to the epithelial cells by means of cytoplasmic projections, although, in previous observations, some intracellular early stages were rarely seen (Redondo et al. 2003). Zschokkella mugilis and Tetracapsuloides bryosalmonae form similar folds and windings between intraepithelial plasmodia and the surrounding epithelial cells (Sitjà-Bobadilla \& Álvarez-Pellitero 1993, Morris \& Adams 2008). These structures together with their junctions play roles in attachment and communication with host cells. Not only the acquisition of nutrients by the myxosporean through this linkage may contribute to the epithelial injury observed, but also the compression suffered by epithelial cells as the disease progresses and the number and size of parasitic forms increases (El-Mansy \& Bashtar 2002, Barassa et al. 2003).

When the infection progressed, parasite stages invaded nearly every fold in the digestive tract and parasitic stages accompanied by dislodged epithelial cells formed clusters of debris that were released to the lumen. The detached enterocytes showed features of apoptosis such as cell rounding and shrinkage, chromatin condensation and nuclear fragmentation. These detached epithelial cells underwent anoikis, a mode of apoptosis triggered by the loss of anchorage, as described by do Vale et al. (2007) in Dicentrarchus labrax infected with Photobacterium damselae ssp. piscicida. Infectious agents are able to induce apoptosis in host cells (Abbasi et al. 2003, Boettner \& Petri 2005) and even that apoptosis and epithelial proliferation are increased in those epithelia under infective pressure (Von Herbay \& Rudy 2000, do Vale et al. 2007). In turbot enteromyxosis it remains unclear if the increase in apoptotic rates in the lining epithelium is induced by the etiologic agent or the anoikis is an attempt to prevent the local spread of the pathogen (Sherman \& Petrak 2005). Nevertheless, in studies conducted by Redondo et al. (2003), the authors interpreted that the epithelial remnants covering the parasites protect them and help to retain their viability in seawater. Therefore, it is possible that anoikis suffered by the enterocytes plays an important role in the spread of the parasite and in the progression of the disease. In fish with severe infections, the presence of

Figs. 16 to 21. Psetta maxima and Enteromyxum scophthalmi. Light microscopy photographs of turbot tissues infected with E. scophthalmi corresponding to severe infection. Toluidine blue stain. Fig. 16. Micrograph of anterior intestine, showing detachment of the epithelial lining from the subepithelial tissue and epithelial remnants in the intestinal lumen. Scale bar $=30 \mu \mathrm{m}$. Fig. 17. Epithelial detachment in the anterior intestine. Note the edematous space between the lamina basal and the dislodged epithelial cells (arrows), as well as the structural changes of the enterocytes, namely, cell rounding and shrinkage. An E. scophthalmi stage enveloped by dislodged epithelial cells in the intestinal lumen can be seen (arrowhead). Scale bar $=20 \mu \mathrm{m}$. Fig. 18. Several clusters of dislodged epithelial cells in the lumen, some of them possessing large rounded empty spaces (arrows). Scale bar $=20 \mu \mathrm{m}$. Fig. 19. Pyloric caeca displaying some completely denuded folds (arrows) and a moderate number of inflammatory cells in the lamina propria-submucosa. Scale bar $=120 \mu \mathrm{m}$. Fig. 20. Micrograph of the anterior intestine. Intestinal fold covered with low cubic cells due to reepithelialization. Note that the new epithelium has already been invaded by the myxozoan (arrowheads). Scale bar $=20 \mu \mathrm{m}$. Fig. 21. Extreme dilatation of blood (arrowhead) and lymphatic (asterisks) vessels in the lamina propria-submucosa of the posterior intestine. Scale bar $=60 \mu \mathrm{m}$ 

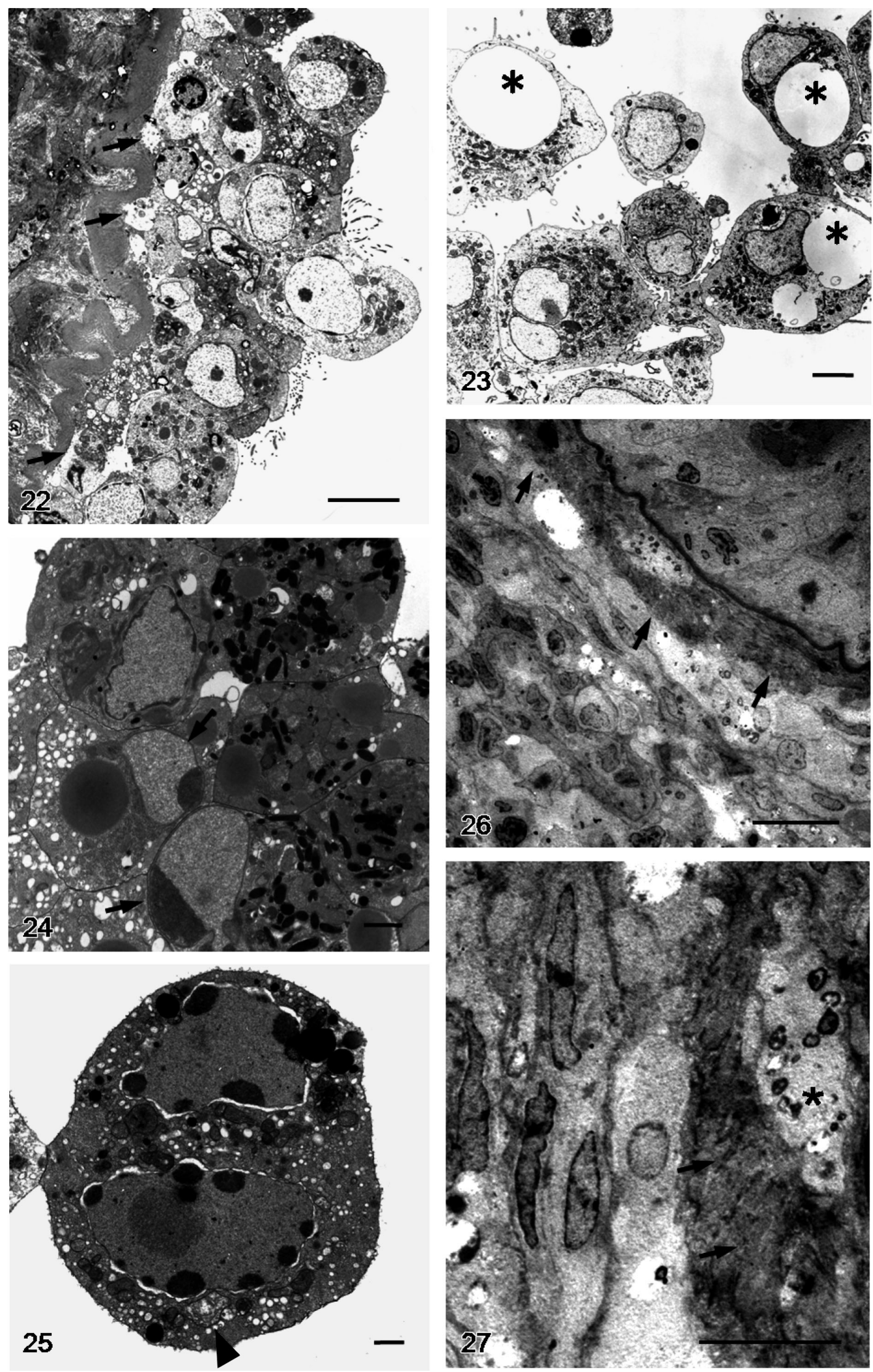
Figs. 22 to 27. Psetta maxima and Enteromyxum scophthalmi. TEM micrographs of turbot tissues infected with E. scophthalmi corresponding to severe infection. Fig. 22. Anterior intestine. Altered enterocytes with a spherical shape, loss of polarization and loss of apical microvilli. Deposition of amorphous, electron-lucent material (arrows) indicates remnants of adhesion between the epithelium and the basal membrane. Scale bar $=5 \mu \mathrm{m}$. Fig. 23. Anterior intestine containing clusters of rounded, degenerated and detached enterocytes with empty spaces of different sizes (asterisks). Scale bar $=2 \mu \mathrm{m}$. Fig. 24. Micrograph of esophagic dislodged cells. Some isolated cells showed evident apoptotic alterations, including cell rounding and fragmentation and/or nuclear condensation (arrows). Scale bar $=1 \mu \mathrm{m}$. Fig. 25. Enterocyte with incipient apoptotic nuclear alterations (fragmentation and condensation of the chromatin at the periphery of the nucleus). Swollen mitochondria showing effacement of cristae are visible (arrowhead). Scale bar $=1 \mu \mathrm{m}$. Fig. 26. Lamina propria-submucosa of pyloric caeca. The connective tissue underlying the mucosal epithelium appeared thin and grossly disorganized (arrows). Many of inflammatory cells located populating the lamina propria-submucosa showed advanced features of both apoptosis and necrosis. Scale bar $=10 \mu \mathrm{m}$. Fig. 27. Higher magnitude micrograph of Fig. 24. Note the disorganization of collagen fibres (arrows), as well as the apoptotic cells embedded in the basal membrane (asterisk). Scale bar $=5 \mu \mathrm{m}$

empty rounded spaces within some clusters of dislodged cells was remarkable. The empty spaces were probably attributable to the release of the parasitic stages from the mucosal remnants that formerly lodged them, representing the area that previously was occupied by the parasite. This supports the hypothesis that apoptosis of the epithelial cells might facilitate the spread of the parasite.

Both apoptosis and necrosis were observed in immune cells located in the lamina propria-submucosa and in the haematopoietic areas of the kidney and spleen. In addition, the lymphohaematopoietic depletion in the spleen and kidney of Enteromyxum scophthalmi-infected turbot described by Sitjà-Bobadilla et al. (2006) was confirmed by the current observations. Determining whether this finding is due to the recruitment and migration of lymphocytes to the digestive tract (Bermúdez et al. 2006b) or to a parasite-induced apoptosis in the immune cells from these organs deserves further investigation.

Other cellular structures changing as a consequence of the infection were the MMCs, which increased in number in both the lamina propria-submucosa and the haematopoietic organs of infected turbot (SitjàBobadilla et al. 2006). This observation supports the hypothesis that the MMCs may be involved in fish immune responses during infections (Bermúdez et al. 2006b, Vigliano et al. 2006).

Some infected turbot showed a regenerative epithelium after detachment of the lining epithelium, which suggests that some fish could overcome the disease and eliminate the parasites, as described by Fleurance et al. (2008) in Enteromyxum leei-infected sea bream. As a matter of fact, some turbot survive enteromyxosis, and the involvement of a protective acquired immune response related to the production of specific antibodies has been suggested (Sitjà-Bobadilla et al. 2007). The reason why few turbot possess the capability to mount an effective response against enteromyxosis is still a matter of study, though the responses at the gastrointestinal level probably play an important role in this enteric infection.
In summary, the present study describes the main histological lesions in turbot infected with Enteromyxum scophthalmi, providing new information about pathogenic mechanisms and host-parasite relationships. Further studies will be necessary to distinguish between early phases of the myxosporean and apoptotic cells at the beginning of the infection, as well as to elucidate the role of apoptosis and other mechanisms in the progress of the disease, in order to better understand the pathogenesis of the enteromyxosis. This knowledge will assist the design of specific treatments for this important disease.

Acknowledgements. This work was supported by the Spanish Ministry of Science and Technology under Project AGL200613158-C03-02/ACU. A.P.L. is the recipient of a predoctoral fellowship of the Programa María Barbeito 2008 (Xunta de Galicia). The authors sincerely thank M. C. Carreira Valle for her excellent technical assistance and $\mathrm{N}$. Alemañ for the critical review of the manuscript.

\section{LITERATURE CITED}

Abbasi M, Kowalewska-Grochowska K, Bahar MA, Kilani RT, Winkler-Lowen B, Guilbert LJ (2003) Infection of placental trophoblasts by Toxoplasma gondii. J Infect Dis 188: 608-616

$>$ Adriano EA, Arana S, Cordeiro NS (2005) An ultrastructural and histopathological study of Henneguya pellucida n. sp. (Myxosporea: Myxobolidae) infecting Piaractus mesopotamicus (Characidae) cultivated in Brazil. Parasite 12:221-227

Ali MA, Abdel-Baki AS, Sakran T, Entzeroth R, Abdel-Ghaffar F (2003) Light and electron microscopic studies of Myxobolus stomum n. sp. (Myxosporea: Myxobolidae) infecting the blackspotted grunt Plectorhynicus gaterinus (Forsskal, 1775) in the Red Sea, Egypt. Parasitol Res 91: 390-397

Álvarez-Pellitero P, Palenzuela O, Sitjá-Bobadilla A (2008) Histopathology and cellular response in Enteromyxum leei (Myxozoa) infections of Diplodus puntazzo (Teleostei). Parasitol Int 57:110-120

Athanassopoulou F, Karagouni E, Dotsika E, Ragias V, Tavla J, Christofilloyanis P, Vatsos I (2004) Efficacy and toxicity of orally administrated anti-coccidial drugs for innovative treatments of Myxobolus sp. infection in Puntazzo puntazzo. Dis Aquat Org 62:217-226 
Barassa B, Cordeiro NS, Arana S (2003) A new species of Henneguya, a gill parasite of Astyanax altiparanae (Pisces: Characidae) from Brazil, with comments on histopathology and seasonality. Mem Inst Oswaldo Cruz 98: 761-765

Bartholomew JL, Smith CE, Rohovec JS, Fryer JL (1989) Characterization of a host response to the myxosporean parasite, Ceratomyxa shasta (Noble), by histology, scanning electron microscopy and immunological techniques. J Fish Dis 12:509-522

Bartosová P, Fiala I, Hypsa V (2009) Concatenated SSU and LSU rDNA data confirm the main evolutionary trends within myxosporeans (Myxozoa: Myxosporea) and provide an effective tool for their molecular phylogenetics. Mol Phylogenet Evol 53:81-93

> Bermúdez R, Alemañ N, Vigliano F, Vázquez S, Quiroga MI, Nieto JM (2006a) Effects of symmetric triazinone (toltrazuril) on developmental stages of Enteromyxum scophthalmi parasitizing turbot (Scophthalmus maximus L.): a light and electron microscopic study. Aquaculture 254: 65-71

Bermúdez R, Vigliano F, Marcaccini A, Sitjà-Bobadilla A, Quiroga MI, Nieto JM (2006b) Response of Ig-positive cells to Enteromyxum scophthalmi (Myxozoa) experimental infection in turbot, Scophthalmus maximus (L.): a histopathological and immunohistochemical study. Fish Shellfish Immunol 21:501-512

Boettner DR, Petri WA (2005) Entamoeba histolytica activates host cell caspases during contact-dependent cell killing. Curr Top Microbiol Immunol 289:175-184

Branson E, Riaza A, Álvarez-Pellitero P (1999) Myxosporean infection causing intestinal disease in farmed turbot, Scophthalmus maximus (L.), (Teleostei: Scophthalmidae). J Fish Dis 22:395-399

> Dezfuli BS, Lui A, Boldrini P, Pironi F, Giari L (2008) The inflammatory response of fish to helminth parasites. Parasite 15:426-433

Diamant A, Lom J, Dyková I (1994) Myxidium leei n. sp., a pathogenic myxosporean of cultured sea bream Sparus aurata. Dis Aquat Org 20:137-141

do Vale A, Costa-Ramos C, Silva DS, Macedo PM and others (2007) Cytochemical and ultrastructural study of anoikis and secondary necrosis in enterocytes detached in vivo. Apoptosis 12:1069-1083

El-Mansy A, Bashtar AR (2002) Histopathological and ultrastructural studies of Henneguya suprabranchiae Landsberg, 1987 (Myxosporea: Myxobolidae) parasitizing the suprabranchial organ of the freshwater catfish Clarias gariepinus Burchell, 1822 in Egypt. Parasitol Res 88: 617-626

Feist SW (2008) Myxozoan diseases. In: Eiras J, Segner K, Wahli T, Kapoor BG (eds) Fish diseases, Vol 2. Science Publishers, Enfield, NH, p 613-82

Fiala I (2006) The phylogeny of Myxosporea (Myxozoa) based on small subunit ribosomal RNA gene analysis. Int J Parasitol 36:1521-1534

> Fleurance R, Sauvegrain C, Marques A, Le Breton A, Guereaud C, Cherel Y, Wyers M (2008) Histopathological changes caused by Enteromyxum leei infection in farmed sea bream Sparus aurata. Dis Aquat Org 79:219-228

Kent ML, Andree KB, Bartholomew JL, El-Matbouli M and others (2001) Recent advances in our knowledge of the Myxozoa. J Eukaryot Microbiol 48:395-413

Lom J, Dyková I (1995) Myxosporea (phylum Myxozoa). In: Woo PTK (ed) Fish diseases and disorders, Vol 1. Protozoan and metazoan infections. CAB International, Wallingford, p 97-148
Lom J, Dyková I $(2006)$ Myxozoan genera: definition and notes on taxonomy, life-cycle terminology and pathogenic species. Folia Parasitol 53:1-36

Mazon AF, Huising MO, Taverne-Thiele AJ, Bastiaans J, Verburg-van Kemenade BM (2007) The first appearance of Rodlet cells in carp (Cyprinus carpio L.) ontogeny and their possible roles during stress and parasite infection. Fish Shellfish Immunol 22:27-37

> Molnár K (2007) Site preference of myxozoans in the kidneys of Hungarian fishes. Dis Aquat Org 78:45-53

> Moran JDW, Margolis L, Webster JM, Kent ML (1999) Development of Kudoa thyrsites (Myxozoa: Myxosporea) in netpen-reared Atlantic salmon determined by light microscopy and a polymerase chain reaction test. Dis Aquat Org 37:185-193

Morris DJ, Adams A (2008) Sporogony of Tetracapsuloides bryosalmonae in the brown trout Salmo trutta and the role of the tertiary cell during the vertebrate phase of myxozoan life cycles. Parasitology 135:1075-1092

> Padrós F, Palenzuela O, Hispano C, Tosas O, Zarza C, Crespo S, Alvarez-Pellitero P (2001) Myxidium leei (Myxozoa) infections in aquarium-reared Mediterranean fish species. Dis Aquat Org 47:57-62

Palenzuela O (2006) Myxozoan infections in Mediterranean mariculture. Parassitologia 48:27-29

Palenzuela O, Redondo MJ, Alvarez-Pellitero P (2002) Description of Enteromyxum scophthalmi gen. nov., sp. nov. (Myxozoa), an intestinal parasite of turbot (Scophthalmus maximus L.) using morphological and ribosomal RNA sequence data. Parasitology 124:369-379

- Quiroga MI, Redondo MJ, Sitjà-Bobadilla A, Palenzuela O and others (2006) Risk factors associated with Enteromyxum scophthalmi (Myxozoa) infection in cultured turbot, Scophthalmus maximus (L.). Parasitology 133: 433-442

Redondo MJ (2005) Estudios sobre el ciclo vital y transmisión de Enteromyxum scophthalmi (Myxozoa), parásito entérico del rodaballo. PhD thesis, University of Valencia

> Redondo MJ, Palenzuela O, Riaza A, Macías A, Alvarez-Pellitero P (2002) Experimental transmission of Enteromyxum scophthalmi (Myxozoa), an enteric parasite of turbot Scophthalmus maximus. J Parasitol 88:482-488

> Redondo MJ, Quiroga MI, Palenzuela O, Nieto JM, AlvarezPellitero P (2003) Ultrastructural studies on the development of Enteromyxum scophthalmi (Myxozoa), an enteric parasite of turbot (Scophthalmus maximus L.). Parasitol Res 90:192-202

> Redondo MJ, Palenzuela O, Alvarez-Pellitero P (2004) Studies on transmission and life cycle of Enteromyxum scophthalmi (Myxozoa), an enteric parasite of turbot Scophthalmus maximus. Folia Parasitol 51:188-198

> Reite OB (2005) The rodlet cells of teleostean fish: their potential role in host defence in relation to the role of mast cells/eosinophilic granule cells. Fish Shellfish Immunol 19:253-267

> Sherman MP, Petrak K (2005) Lactoferrin-enhanced anoikis: a defense against neonatal necrotizing enterocolitis. Med Hypotheses 65:478-482

Sitjà-Bobadilla A, Álvarez-Pellitero P (1993) Pathologic effects of Sphaerospora dicentrarchi Sitjà-Bobadilla and Alvarez-Pellitero, 1992 and S. testicularis Sitjà-Bobadilla and Alvarez-Pellitero, 1990 (Myxosporea: Bivalvulida) parasitic in the Mediterranean sea bass Dicentrarchus labrax L. (Teleostei: Serranidae) and the cell-mediated immune reaction: a light and electron microscopy study. Parasitol Res 79:119-129

Sitjà-Bobadilla A, Redondo MJ, Bermúdez R, Palenzuela O 
and others (2006) Innate and adaptive immune responses of turbot, Scophthalmus maximus (L.), following experimental infection with Enteromyxum scophthalmi (Myxosporea: Myxozoa). Fish Shellfish Immunol 21:485-500

Sitjà-Bobadilla A, Palenzuela $O$, Riaza $A$, Macías MA, Álvarez-Pellitero P (2007) Protective acquired immunity to Enteromyxum scophthalmi (Myxozoa) is related to specific antibodies in Psetta maxima (L.) (Teleostei). Scand J Immunol 66:26-34

Sitjà-Bobadilla A, Calduch-Giner J, Saera-Vila A, Palenzuela O, Álvarez-Pellitero P, Pérez-Sánchez J (2008) Chronic exposure to the parasite Enteromyxum leei (Myxozoa: Myxosporea) modulates the immune response and the expression of growth, redox and immune relevant genes in gilthead sea bream, Sparus aurata L. Fish Shellfish Immunol 24:610-619

Vigliano FA, Bermúdez R, Quiroga MI, Nieto JM (2004)

Editorial responsibility: Sven Klimpel,

Düsseldorf, Germany
Kinetics of goblet and rodlet cells in the digestive tract of E. scophthalmi-infected turbot. In: Alves A, Méndez A, Gärtner F, Castaño M (eds) Proc 12th Annual Meeting of the Portuguese Society of Animal Pathology and 16th Annual Meeting of the Spanish Society of Veterinary Pathology. Jun 2-4, 2004, Vila Nova de Famalicào

Vigliano FA, Bermúdez R, Quiroga MI, Nieto JM (2006) Evidence for melano-macrophage centres of teleost as evolutionary precursors of germinal centres of higher vertebrates: an immunohistochemical study. Fish Shellfish Immunol 21(4):467-71

Von Herbay A, Rudi J (2000) Role of apoptosis in gastric epithelial turnover. Microsc Res Tech 48:303-311

Yokoyama H, Ogawa K, Wakabayashi H (1990) Chemotherapy with fumagilin and toltrazuril against kidney enlargement disease of goldfish caused by the myxosporean Hoferellus carassii. Fish Pathol 25:157-163

Submitted: September 10, 2009; Accepted: January 19, 2010 Proofs received from author(s): March 30, 2010 